\title{
Challenges facing local NGOs in resource mobilization
}

\author{
Rehema C. Batti \\ Ongoing PHD student in the School of Management, Atlantic International University, 900 Fort Street Mall 40 Honolulu, Hawaii, USA \\ Email address: \\ rehemabatti2012@gmail.com \\ To cite this article: \\ Rehema C. Batti. Challenges Facing Local NGOs in Resource Mobilization. Humanities and Social Sciences. \\ Vol. 2, No. 3, 2014, pp. 57-64. doi: 10.11648/j.hss.20140203.12
}

\begin{abstract}
Development organizations need resources to help them continue providing services to the community. Non Govermental Organizations (NGOs) for a long time have relied on the generosity of donors to support their project activities through grants and donations. However organizations have realized that such funding sources are often insufficient to meet needs and rising costs for project implementation. In Africa despite vast differences among the NGOs most share a common challenge of unlimited needs chasing limited resources. Local NGOs face difficulties securing enough funds because the projects undertaken require substantial amounts of resources, both financial and non-financial due to high poverty levels in most parts of the continent. Resource mobilization requires a lot of time and skills to seek resources from different sources and the pressure to mobilize resources may lead the organizations to use methods that compromise the values they are fighting for through their work.
\end{abstract}

Keywords: Resource Mobilization in Local NGOs, Fundraising in NGOs, Challenges in Resource Mobilization

\section{Introduction}

Resource mobilization is a valuable component for strengthening an NGO. Unfortunately there is a lot of competition for donor resources and in many cases for an organization to secure resources it depends on how well it can compete with other organizations to raise funds; and on how good it is at exploring other ways to source for resources.

Those NGOs fortunate enough to have adequate resources to support their current operations still face uncertainty over future funding. Many organizations wonder whether the donors will keep supporting program costs or will they shift their focus to other more pressing needs. At times a donor runs out of business and can no longer provide resources. These are some of the scenarios that create uncertainty over donor funding and makes it extremely difficult for NGOs to plan and implement their project activities consistently.

The uncertain continuity of donor funding, forces an NGO to live a project to project existence, which makes it difficult to design and expand project activities to improve the quality of services. However the common mistake that local NGOs make is to become over dependent on a single source of funding. When that source reduces or dries up the organization struggles to generate new funding when it is too late, hence programs are compromised or terminated.

Therefore, the task facing NGOs currently and in the future is and will be to explore additional mechanisms to boost financial stability without sacrificing the mission of their organizations. This paper seeks to highlight the challenges currently faced, make recommendations and share emerging trends in resource mobilization that organizations can use to build a more sustainable resource base.

\section{Perspectives in Resource Mobilization}

\subsection{Definition Resource Mobilization and Fundraising}

- $\quad$ Resource mobilization is a process whereby resources both financial and non financial resources are mobilized either externally or internally to support organization activities.

- Fundraising is the act of persuading people or organizations to raise money for a cause. Fund-raising is the activity of collecting money to support a charity or political campaign or organization.

Fundraising means that funds are elsewhere and approaches need to be explored to access the funds. Resource mobilization has additional two concepts; one is that non-financial resources are crucial and secondly some resources can be generated by the organization internally rather than sourced from others. 


\subsection{Sources for Funding or Resources}

There are two categories for sourcing of funds or resources

\subsubsection{Conventional}

Individual philanthropy, Private foundations, corporate agencies, government and foreign development agencies

\subsubsection{Non Conventional Means}

Membership fees, businesses, income generating activities, Prizes/Awards;

It is important for organizations to understand funding sources within categories that they have not fully explored and design mechanisms of accessing them. There are three ways to mobilize resources as follows; accessing existing resources through private and public sources, generating new wealth and capitalizing on non-financial resources

\subsection{Resource Mobilization Framework}

Resource mobilization process is made up of 3 aspects as follows the resources, mechanism and the providers

- Mechanism:

These include submission of grant proposals, special events, small business and application for donation.

- Means/Resources:

These include the following cash, technical support, human resource, subsidized service and facilities, equipment, information and goods.

- $\quad$ Resource Providers:

These may include; International NGOs, bilateral and multi-lateral agencies, cooperatives, government and businesses among others

\section{Sustainability and Resource Mobilization}

\subsection{Concept of Sustainability of Organizations}

There is a lot of talk and literature on what, how and whys of organization sustainability. Many organizational leaders are striving to understand and explore ways to build a sustainable organization that will ensure they are making a positive impact on the society and the environment in which it works.

There is evidence in literature that shows that organizations are struggling to grow consistently over a period of 10 years. Many local NGOs in Africa are smaller, privately-owned, group owned or family-owned and are short-lived as they are unable to achieve long-term, consistent growth or improve performance.

For many local NGOs in Africa, there are high rates of senior management turn-over, internal wrangles caused by power structures, poor financial reporting and the intense scrutiny of financial expenditures by donors and governments hence management focus remains biased on short-term performance. This happens because the reward systems do not recognize and value performance in the long term and this means these organizations have objectives which were never intended to be sustainable in the long-run.

This scenerio makes one to conclude that the way organizations are managed is quite "unsustainable" and unfortunately has an impact on how an organization mobilizes and manages resources. It is vital for organizations to consider sustainability in a new more comprehensive way if they are to succeed in the future.

Sustainability is not only linked to how an organization is able to mobilize and generate ongoing resources required to sustaining its mission and undertaking quality work but also there is a link between quality and sustainability.

Quality of services is often one of the critical ingredients in achieving an organization's sustainability. Organizations are required to adopt crosscutting quality assurance systems to ensure quality of services is not compromised overtime as this is key to ensuring that services undertake by the organization remain on demand.

Many people equate an organization's sustainability with its financial strength, but this alone becomes irrelevant over time. Mavuto $(2013: 88)^{1}$ lists some characteristics of a sustainable NGO which include strategy, established constituency, sound organizational governance, enlightened management, learning culture and good public relations.

\subsection{Resource Mobilization the Key to Sustainability}

Organizations without a strong sustainability culture will not grow. A good sustainability culture exists when all staff respect their donors and want to understand and meet their needs. A good culture exists when staff members value program and sustainability as two necessary components of a successful organization and appreciate their interconnectedness.

An organizational culture that is flexible helps an organization in looking for ways to maximize resources, in finding innovative ways of raising funds, or carrying out programs in challenging environments.

However it is important for organizations to realize that the sustainability of an organization does not only depend on the resources an organization has but it is also affected by the following: existence of competent staff, supportive policies, internal systems to manage assets, an organization's ability to establish relationships with individuals and organizations and organizational culture that reinforces sustainability efforts.

When an organization is competing for resources and other support in a very tight market place the organization's appeal has to be different, better, "cheaper" and unique. A donor has no reason to select an organization over another if there no evidence of innovativeness or value in supporting an organization and therefore it is crucial to view an organization's mission from the perspective of current and potential donors and emphasize those aspects of an organization's work which are appealing from a donor's perspective

${ }^{1}$ Mavoko Kapyepye (2013), Resource mobilization for NGOs in the developing world. London. Adonis and Abbet Publishers Limited 


\section{Challenges Facing NGOs in Resource Mobilization}

NGOs are operating under a highly resource competitive environment. The challenges that NGOs encounter in resource mobilization efforts can be divided into external and internal challenges.

\subsection{External Challenges}

\subsubsection{Donor Country Priorities Changing}

Many at times NGOs face dictation of priorities from donors hence organizations shift focus or are not eligible to apply for the funds as they are not meeting the donor priorities. Thomas Parks $(2008: 213)^{2}$ noted that an NGO faced shortfalls when the major bilateral donors were shifting priorities towards economic development and others outside the traditional scope of the organization.

\subsubsection{Criteria being Used/Applied to Organizations}

Donor's preferences have continued to change and they have become increasingly selective. One notes that different donors apply different conditions on aid, for example specify projects that can be supported within their budget, working in partnership or collaboration with others, geographic cover, sector and a properly constituted organization.

\subsubsection{Donors Conditional Ties}

In the donor world the funding trends are changing. We see donors are using basket funding or sometimes shift in funding from NGOs to focus on government institutions and hence the NGOs end up competing for the same funds with the government institutions that have resources and capacity to mobilize for resources. Mavuto $(2013: 23)^{3}$ states that restrictions given to organizations for example not allowing them to engage with another donor during the period they are funding the organization also affects NGOs from diversifying their donor sources.

\subsubsection{Political Interference}

Government policies and political climate increase bureaucratic red tape for NGOs mobilizing resources externally. Where there is political instability donors will either not release funds or they reduce or enforce stringent measures.

Government attitude and perceptions of NGOs have not been good in many African countries and some organizations have been considered by the government as a threat. This has led to some being deregistered or been given restrictions for sourcing funds from external donors for example in Ethiopia.

\footnotetext{
${ }^{2}$ Parks Thomas (2008), The Rise and fall of donor funding for advocacy NGOs: Understanding the impact. Development in Practice, Volume 18,No2 April 2008 GFP.www.globalpolicy.org/ngos/introduction: funding for NGOs.html

${ }^{3}$ Mavoko Kapyepye (2013), Resource mobilization for NGOs in the developing world. London. Adonis and Abbet Publishers Limited
}

\subsubsection{Rules and Regulations within a Country for Accessing Government Funds}

The rules and regulations that govern accessing and applying for government funds and resources make it difficult for organizations to access resources. For example in Kenya a policy of funding one $\mathrm{CBO} / \mathrm{NGO}$ bi-annually per division is seen as an obstacle to the resource empowerment NGOs.

\subsubsection{Donor Prejudices}

Organizations that have a good track record can easily access resources. Cases of funds or resource embezzlements are very serious and donors talk on who has done what and good track record is important. According to an article published by IRIN (2011) many young organizations face the challenge of not being known and donors do not give money as they are not aware of the organization competencies or track record.

\subsubsection{Natural and Manmade Occurrence e.g. Floods, Earthquakes, Wars}

When natural disasters occur most donor funds get diverted to support relief programs and many local NGOs lack the capacity or expertise to undertake relief projects and during this time fewer funds are directed to normal development programs.

Countries that are experiencing conflict experience a decrease in resources available to NGOs as donors do not want to fund NGOs in areas of conflict as perceive the funds will be diverted and purchase of weapons or it will become difficult to attain results in conflict prone areas.

\subsubsection{Competition from "Political NGO"}

Some NGOs are directly or indirectly linked to political parties within their countries country and because they are politically connected they easily lobby for development agencies for funding to 'alleviate poverty' in their constituencies and hence those with no political association end up not accessing the much required funds to support genuine cases of poverty.

\subsubsection{Competition among NGOs in the Same Sector}

Duplication of resources is seen in the activities of some NGOs. For example where there are about ten or more NGOs within the same geographical area and alloffer the same services at the expense of other areas that require equal attention. This raises competition among the NGOs instead of cooperation and unfortunately at times these are not the areas where the donors what to focus on.

There is also a challenge of increased competition between NGOs for funds especially against larger, established NGOs that are known by international donors due to their involvement in relief activities during famine or floods. This puts the emerging NGOs under immense

\footnotetext{
4 IRIN (2011),Foreign funding critical for NGO survival. Nottingham University centre for Research in Economic Development and International Trade.(October 2011)GFP.www.globalpolicy.org/ngos/introduction: funding for NGOs.html
} 
pressure to prove themselves to international donors of their capability to manage resources where aid flow is declining.

\subsubsection{Type of Network Involved in}

Networks that NGOs are engaged in may hinder their ability to access and mobilize resources effectively. This is because some networks are not well thought out and hence organizations do not gain visibility, experience or access new avenues for resource mobilization. In this case, the networks that the NGOs joined did not add any value in the area of resource mobilization.

\subsection{Internal Challenges}

NGOs are expected to initiate, design and implement projects that can be scaled up by governments and donors. However, in addition to external challenges, NGOs also have major internal challenges

\subsubsection{Capacity Limitation within Organizations}

There is significant capacity limitation among indigenous NGOs in terms of human resource and due to having insufficient staff then to pursuing appropriate funding or resources remains elusive to many. For example in Kenya, it was noted that Isinya division had about 484 CBOs of various types formed to address the poverty/household ill health experienced in the area. However, only $25 \%$ of these CBOs were found to be actively implementing projects at micro level, the rest remained inactive due to inability to mobilize the required resources for implementing their mandates. (Beverly etal 2012:128)

\subsubsection{Accountability and Transparency}

Many organizations fail in the two central pillars of good governance that is transparency and Accountability. NGOs sometimes fail to meet the requirements imposed a country's or donors legal system and this makes them lose the public's trust. Many organizations lack sound systems for financial management, program monitoring and evaluation and managing overall program performance that ensure they consistently earn stakeholders trust. For example organizations have been accused of excessive or improper compensation for chief executives and board members, conflict of interest in organizations transactions, non remittance of taxes and unethical behavior. These accusations bring suspicions on the transparency of NGOs and stringent measures are imposed that make it even more difficult to get resources.

\subsubsection{Founder Syndrome}

Many local organizations' leadership face this syndrome. This is whereby the founder or founders tend to control and manage the affairs of the organization with minimal participation from other members. For example a CEO or board members will not allow other staff to engage in

\footnotetext{
${ }^{5}$ Beverly Otieno, Strapola Mala, Hazel Mumbo, Fredrick Aila and Odhiambo Odera (2012) Factors affecting mobilization of Kenyan resources for health and development. International Journal Social Science and Education(2012) Volume 3:Issue 1
}

resource mobilization or the leaders become too comfortable with the current methods of resource mobilization and are not willing to explore other new ways.

\subsubsection{Inadequate Strategic and Operational Plans}

No strategic plans that guide the organization to know what the objectives are and enable the organization identify the resources needed. Most strategic plans developed are for donor purposes only and do not reflect the actual needs to be addressed by the communities.

\subsubsection{Inadequate Networking Skills}

Networking is a common term frequently used by NGOs sector in many African countries, but rarely practiced. Many NGOs lack networking skills and instead are seen competing for resources than working together towards common interest. Many donors are currently looking to fund organizations that are in networks or working together.

\subsubsection{Inadequate Awareness on Available Opportunities}

There are windows of opportunities that exist within countries that sometimes NGOs fail to exploit due to lack of awareness that the opportunities exist. For example according to Beverly etal(2012:129) ${ }^{6}$ indicates that government funds available were not accessed by civil society organizations due to inadequate awareness about the availability and the procedures required to access the funds.

\subsubsection{Governance}

NGOs in many countries do not have effective governance structures and where a board exists, they are rarely effective in providing strategic leadership in ensuring resources are mobilized. Mavuto $(2013: 86)^{7}$ states that boards are supposed to provide guidance and oversight to the operations of the NGO. However many boards are not aware of their role in resource mobilization.

The presence and extent of involvement of management and governance structures in NGOs influenced their ability to mobilize resources. Many times NGOs did not have governance instruments such as constitutions, policies and guidelines and this tended to scare off potential donors.

\subsubsection{Minimal Communication and Branding}

Many NGOs are not able to communicate effectively who they are, what they do, and their achievements. This inability to communicate means the visibility of the organization is poor and they are not able to effectively market their programs. This eventually affects their capacity to mobilize resources

Many at times organizations lose the opportunity to get resources as donors or stakeholders are not aware of the presence of the organization within the area, sector or country.

\section{Conclusion and Recommendations}

\footnotetext{
${ }^{6} \operatorname{Ibid}(2012: 129)$

${ }^{7}$ Mavoko Kapyepye (2013), Resource mobilization for NGOs in the developing world. London. Adonis and Abbet Publishers Limited
} 
Currently in the African continent, many local NGO depend on external donor funding and resources to run their organizations but unfortunately there is also a lot of competition for the money and resources. In many cases the survival of an organization is dependent on how well it can compete with other organizations and on how good it is at finding other ways to source for resources.

\subsection{Recommendations to Address Challenges}

The following are some recommendations to address the challenges NGOs face:

\subsubsection{Understand the Resource Mobilization Cycle}

The resource mobilization cycle is a tool used by strategic organization to help plan, monitor and develop their resource mobilization activities. It involves 3 phases

- $\quad$ Planning-assessment and design element

- Act-implementation(identify, engage, negotiate, manage and report and communicate results) ongoing process

- $\quad$ Reflect on the lessons learned and revise strategy for purposes of redesign. The action plan and strategy are monitored and the organization reflects on successes and challenges then through the lessons learned they tailor and refocus strategy for greater success.

\subsubsection{Understand the External Environment}

Organizations need to critically understand and evaluate the external environment to understand the factors that affect their resource mobilization efforts.

\subsubsection{Appreciate and Analyze Competition}

Increased competition for scarce grant resources requires organizations to start thinking of new options for diverse and multiple funding streams that will support organizations to undertake their projects. According to Li Yuwen $(2011: 15)^{8}$ raising funds has become an important aspect for NGOs. For many organizations competition has a negative connotation and is reserved for use by private or for the profit sector. It is often seen to mean dominating the market by destroying or engulfing your competition. For those that see themselves as collaborative and sector building being competitive sounds unethical and they wonder why they have to compete.

However, understanding organizations within one's sector or other sectors needs to be an integral part of an organization's environmental scan. In doing so an organization may discover what the other organization does threatens the sustainability or presents new opportunities for mobilizing resources through doing a joint program.

\subsubsection{Develop and Manage a Resource Mobilization Plan}

Organizations need to envision where they want to be in three- five years and design and implement programs based on the genuine needs of the target stakeholders or community.

\footnotetext{
${ }^{8}$ Yuwen Li (2011) NGOs in China and Europe: Comparison and Contrast. Farnham, Surrey, England. Ashgate
}

Organizations need to consider resource partners interests in terms of thematic focus and geographic coverage. The identification of resource partners should be seen as an ongoing process and organizations need to continuously update details and focus of the potential resource partners.

Resource mobilization from various kinds of sources and diverse types of resources will decrease an organization's financial risk. One of the gap that many organizations have is too rely heavily on one mechanism for mobilizing resources. Organizations need to determine and set resource mobilization targets and thereafter select mobilization tools.

The resource mobilization strategy should be monitored, discussed and documented and improvements made to the strategy and action plan developed.

\subsubsection{Formation of a Resource Mobilization Team/Committee}

Organizations that have an active resource mobilization committee seem to be effective and successful in their resource mobilization efforts. This is important especially where NGOs do not have a systematic practice of resource mobilization because of limited staff who are busy doing lot of work at the implementation level.

The organization should consider selecting staff and other interested stakeholders with experience and expertise in the field to form a resource mobilization committee. At another level, the board should form a resource mobilization team that over-sees resource mobilization efforts and commits itself to ensure board member involvement.

\subsubsection{Enhancement of Organization's Internal Capacity}

Resource mobilization is a continuous process and it is important for an organization to build its internal capacity to mobilize resources. Organizations sometimes underestimate the time, resources and skills involved in resource mobilization and also maintaining good communication and relations with donors. It takes resources to raise resources and organizations need experienced and skilled personnel and board members in resource mobilization if they are to be successful to get resources.

\subsubsection{Leadership Role in Resource Mobilization}

Resource mobilization is a strategic process within an organization carried out at the executive level and should not be looked at as a different or minor task within the organization's management team. According to Susan DiMattia (2008:26) ${ }^{9}$ it is important to have someone at the top with the belief, energy and time to spearhead fundraising efforts.

NGO leaders are sometimes forced to follow the money and this allows donors to dictate the scope and direction of their activities, or else receive no funds at all. Hence it is crucial for an organizations leadership to articulate the vision for what they want the organization to achieve and what will be the impact of the success and how the interest of the potential funders will be realized without compromising

${ }^{9}$ DiMattia Susan (2008) Getting the money you need .Relationship fundraising. Online January 2008;32(1) 22-26. 
the organization mission.

\subsubsection{Transparency and Accountability for NGOs}

A good reputation is linked with integrity and the reputation of an organization's and its individual players are its most valuable asset and its highest risk.(Pettey J 2008:5) ${ }^{10}$ An organization having an accountable style of working can expand its relations and contacts quickly.

It is common knowledge that the NGO sector in many countries is being watched by government, donors, press, and the general public and creating and maintaining a good, credible public image in such an atmosphere of suspicion and cynicism is a tremendous challenge for many organizations. According to Pettey Janice (2008: xv) ${ }^{11}$ without public trust fundraising cannot happen and if people don't believe an organization will use their money appropriately, they will simply not give.

\subsubsection{The Quality of Financial Management and Accounting}

Organizations that have financial management systems that meet the standards required by external donors is another factor that contributes to an organizations ability to mobilize resources. Donors are comfortable with an organization that has clear financial reporting and auditing arrangements and where adequate monitoring and attribution of costs to activities and results exists.

Clear accounting systems to distribute and track that resources get to where they are intended are things that donors appreciate. Acknowledging a donors resource contribution through managing, monitoring and reporting on the use of resources vis a vis agreed mechanisms which are often spelled out in the agreements is crucial to maintain good relations with the donor and forms a foundation for potential ongoing resources and must not be overlooked.

\subsubsection{Continuous Learning and Improvement in Resource Mobilization Strategies}

Frostein Sarah (2013:21) ${ }^{12}$ states that organizations need to base their fundraising on the behaviour of donors by monitoring feedback and appeals sent to them. This means planning an event where donors have an interest.

One organization reviewed their process of conducting first time meetings with potential donors that was initially done by staff and instead used a consulting company and set up first time meetings with potential donors this freed the staff from organizing such events to concentrate more on the follow-ups and deepening relationships with donors.(Hall 2013:8) ${ }^{13}$

Other methods would include tracking fundraising success and providing rewards or bonus to individuals and

\footnotetext{
${ }^{10}$ Pettey Janice (2008) Ethical fundraising: A guide for nonprofit boards and fundraisers. Hoboken N.J Wiley,

${ }^{11}$ Ibid (2008:xv)

${ }^{12}$ Frostenson Sarah (2013) Don't think weekend appeals don't work. Chronicles of Philanthropy (serial online) June 27,2013:25 (15)21.

${ }^{13}$ Hall Holly, Big changes help hospital attract more big gifts faster. Chronicles of Philanthropy (serial online),2013: 25(10)8.
}

teams once the goals are achieved or exceeded(Berkshire 2013:20) ${ }^{14}$.For example Save the Children found a creative way of saying thank you to its donors by using the fastest talking woman to say thank you. (Flandez 2013:17) ${ }^{15}$

\subsubsection{Sustainability and Relevance of the Project to be Supported}

Strong relationship with donors is important, however as organizations seek resources they should be aware of the possibility of getting one time resources or a donor and hence there is need to ensure that the project will be self sustaining once the donor support is over.

There are evidences that indicate that NGOs programs have the problems of phase-out and sustainability which are terms frequently mentioned in development programs. NGO projects undertaken are ideally expected to bring change among the needy people. However change will only be possible if NGOs are able to sustain their programs and this is possible when NGOs start their programs with good phase-out strategy.

Organizations need to realistically plan to see whether the cost of the project can be absorbed into the regular budget in the future fiscal years and this provides a basis of negotiating with the donor on how long an organization needs support.(DiMattia 2008:26) ${ }^{16}$

\subsection{Emerging Resource Mobilization Trends}

\subsubsection{Internet Fundraising}

Organizations in Africa could consider using internet as a fundraising mechanism. This allows the funder the possibility of giving continuously and costs less. For example Network for Good raised \$300 million from more that 50,000 different nonprofit and a total of $\$ 7$ billion was contributed in 2008(Hoefer 2012:362) ${ }^{17}$

According to Hoefer (2012:364) ${ }^{18}$ affiliate marketing can also contribute to bringing in new streams of contribution and unrestricted funds.

\subsubsection{Developing Social Enterprise Using the Social Business Model}

According to Yunus (2010:1) ${ }^{19}$ social business involves solving a social problem by using business methods which include creation and sale of products and services. In starting a social business, one does not start with a focus on the business, but identifies a social problem and then tries to

\footnotetext{
${ }^{14}$ Berkshire Jennifer (2013) A university offers Flexibility and financial rewards to keep fundraisers happy. Chronicles of Philanthropy (serial online) Jan 17, 2013: 25(5)20.

${ }^{15}$ Flandez, Raymund (2013) Fundraisers find success with simple appeals, wild ideas and off beat campaigns. Chronicles of Philanthropy (serial online) Jan 17, 2013: 25(5)17

${ }^{16}$ DiMattia Susan (2008) Getting the money you need .Relationship fundraising. Online January 2008;32(1) 22-26.

${ }^{17}$ Hoefer R.( 2012) From website visitor to online contributor. Three internet fundraising techniques for non profits. 57(4)361-365

${ }^{18} \operatorname{Ibid}(2012: 364)$

19 Muhammad Yunus (2010), Building social business. New York. Public Affairs
} 
address it by incorporating a business solution for it. (Yunus 2010:35 $)^{20}$

I believe this is an interesting area that NGOs can explore that will help them address a social need but have income that will ensure the projects is sustainable. Yunus $(2010: 58)^{21}$ advises in his book that to start a social business one needs to identify a need and match it with the capabilities and talents. An organization needs to clarify the objective of the business and make sure they get the desired result from the project then come up with a product or service to serve as a vehicle for achieving this objective.

\subsubsection{Local Resource Mobilization}

The generation of local resources through saving and investing wisely is the essential foundation of sustained development for any organization. The high dependence on external resources puts limits on organization's policy space and creates some vulnerability.

Local resource mobilization is gaining popularity and is becoming necessary as donor resources continue to decline. NGOs typically benefit from local contribution of time from communities, manual labour and cash towards a development project however this is normally not given much weight when it comes to resource mobilization mechanisms. In future local resource mobilization will provide a crucial viable long-term financing basis for development projects undertaken by local NGOs.

\subsubsection{Resource Mobilization from Private Sector Organizations and Individuals}

Many resource mobilization efforts of organizations are focused on fund raising from international institutional donors. If organizations desire to diversify their sources of resources, they may have to revise their current approaches, which are only focused on attracting external grants and accommodate options of sourcing resources from businesses and individuals.

Organizations in their bid to diversify funding resources will need a paradigm shift to tap into corporate philanthropy and individual donors. According to IRIN (2009), ${ }^{22}$ Fifty one percent $(51 \%)$ of humanitarian funding for 114 NGOs came from private sources and it also cites that Medicines San Frontier (MSF) received $86 \%$ of its funds from private sources. Private sources allow organizations to respond quickly and they have fewer restrictions.

According to Bray $(2008: 86-87)^{23}$ organizations should also consider recruiting individual supporters as it is worthwhile as they come with few strings attached. While grants from a foundation maybe much more than from individuals, but they may come with many restrictions.

Corporate social responsibility is an emerging field in many African countries and gradually catching up with

\footnotetext{
${ }^{20} \operatorname{Ibid}(2010: 35)$

${ }^{21} \operatorname{Ibid}(2010: 58)$

22 IRIN (2009),Global: Individuals give NGOs more funds than donors.GFP.www.globalpolicy.org/ngos/introduction: funding for NGOs.html

${ }^{23}$ Bray Illona (2009) Effective fundraising for non profits: Real world strategies that work. Berkeley. Ebook
}

international standards. Local organizations will benefit from this trend of corporations donating to local organizations.

In conclusion, an important part of planning for an NGO is increasing financial security and becoming independent of donors. This may be a realistic goal for some NGOs who have the ability to self-generate funds to cover overhead costs yet others may still legitimately continue to rely on grants and donations, at least for now, as this may be the available approach.

There is no right or wrong answer and therefore it is up to each organization to review the options available and to choose the most appropriate mechanism for resource mobilization and move from only focusing on mobilizing financial resources.

Organizations as they pursue resources from donors and others sources they need to recognize that sustainability is not only about getting resources/funds but also requires a solid organization, strong programs that determine which project activities and implementation strategies are most appropriate to achieve an organizations mission and objectives and ensure it remains relevant year after year.

An organization cannot market itself and what it does unless it has good programs. On the other hand, if no one wants to invest in an organization's programs, they have little chance of benefiting society and being sustained.

\section{Acknowledgements}

I would like to appreciate the invaluable support I receive from my University advisor Dr Valcin and the university team.

\section{References}

[1] Beasely Thomas W (2009) Poverty in Africa. New York: Nova Science Publishers.

[2] Berkshire Jennifer (2013) A university offers Flexibility and financial rewards to keep fundraisers happy. Chronicles of Philanthropy (serial online) Jan 17, 2013: 25(5)20.

[3] Beverly Otieno, Strapola Mala, Hazel Mumbo, Fredrick Aila and Odhiambo Odera (2012) Factors affecting mobilization of Kenyan resources for health and development. International Journal Social Science and Education (2012) Volume 3: Issue 1

[4] Bray Illona (2009) Effective fundraising for nonprofit: Real world strategies that work..Berkeley:

[5] DiMattia Susan (2008) Getting the money you need .Relationship fundraising. Online January 2008;32(1) 22-26.

[6] Flandez, Raymund (2013) Fundraisers find success with simple appeals, wild ideas and off beat campaigns. Chronicles of Philanthropy (serial online) Jan 17,2013: 25(5)17.

[7] Frostenson Sarah, (2013) Don't think weekend appeals don't work. Chronicles of Philanthropy (serial online) June 27,2013: 25(15)21. 
[8] Hall Holly, Big changes help hospital attract more big gifts faster. Chronicles of Philanthropy (serial online),2013: $25(10) 8$.

[9] Hoefer R ( 2012) From website visitor to online contributor. Three internet fundraising techniques for nonprofits. 57(4)361-365.

[10] IRIN (2009) Global: Individuals give NGOs more funds than donors.GFP.www.globalpolicy.org/ngos/introduction: funding for NGOs.html

[11] IRIN (2011) Foreign funding critical for NGO survival. Nottingham University centre for Research in Economic Development and International Trade.(October 2011)GFP.www.globalpolicy.org/ngos/introduction: funding for NGOs.html

[12] Mavoko Kapyepye (2013) Resource mobilization for NGOs in the developing world. London. Adonis and Abbet Publishers Limited

[13] Muhammad Yunus (2010) Building social business. New York. Public Affairs

[14] Parks Thomas (2008) The Rise and fall of donor funding for advocacy NGOs: Understanding the impact. Development in Practice, Volume 18,No 2 April 2008 GFP.www.globalpolicy.org/ngos/introduction: funding for NGOs.html

[15] Pettey Janice Gow (2008) Ethical Fundraising: A guide for nonprofit boards and fundraisers. Hoboken. N.J. Wiley \& Sons.

[16] Yuwen Li (2011) NGOs in China and Europe: Comparison and Contrast. Farnham, Surrey, England. Ashgate Publishing Limited. 